\title{
The president speaks: prevention is best: lessons from protecting the ozone layer
}

\author{
Ashley Woodcock
}

\begin{abstract}
The Montreal Protocol was signed 25 years ago. As a result, the irreversible destruction of the ozone layer was prevented. However, stratospheric ozone will not recover completely until 2060 and the consequent epidemic in skin cancer cases will persist until 2100. Many millions of patients with asthma and chronic obstructive pulmonary disease have safely switched from chlorofluorocarbon (CFC)powered metered-dose inhalers (MDIs) to either hydrofluorocarbon (HFC) or DPIs. China will be the last country to phase out CFCs by 2016. HFCs are global warming gases which will be controlled in the near future. HFCs in MDIs may be phased out over the next 10-20 years.
\end{abstract}

In November 2012, the Meeting of the Parties to the Montreal Protocol for the Protection of the Ozone Layer celebrated its 25th anniversary in Geneva. There is much to celebrate since the Montreal Protocol has been the most successful in the UN Environment Programme and is unique in being signed by all 196 members of the UN.

\section{STRATOSPHERIC OZONE}

Stratospheric ozone is critical in shielding the Earth and its life forms from excessive ultraviolet B (UVB) radiation. Reductions in ozone increase skin cancer and cataracts, and have major effects on plankton and crops. The Montreal Protocol controls the production of a range of chemicals that deplete stratospheric ozone, including methyl bromide used as a soil sterilant in agriculture, halons for fire extinguishers in aeroplanes and chlorofluorocarbons (CFCs), which were widely used in refrigeration, foam blowing and as aerosol propellants, especially in metered-dose inhalers (MDIs) used for asthma and chronic obstructive pulmonary disease (COPD). CFCs are very stable with an atmospheric lifetime of 100 years or more,

Correspondence to Professor Ashley Woodcock, Institute of Inflammation and Repair, University of Manchester, Manchester Academic Health Science Centre, Manchester, M23 9LT, UK; ashley.woodcock@ manchester.ac.uk and peak production in the 1980s was over 1 million tonnes/year. There are still a lot of CFCs in the stratosphere and will be for many decades to come.

\section{OZONE DEPLETION}

In 1974, in a literally world-saving paper, Mario Molina and Sherwood Rowland described the exponential increase of CFCs in the stratosphere and predicted that CFCs would catalyse the breakdown of stratospheric ozone during the Antarctic winter, with potentially serious impact on life on Earth. ${ }^{1}$ In spite of cynicism from the chemical industry and some scientists, their prediction came true a decade later. However the 'Ozone hole' found in early spring 1985 over Antarctica was much more severe than anyone had predicted. By 1987 airborne studies had confirmed that ozone depletion was driven by chlorine chemistry. ${ }^{2}$

The proof of hypothesis accelerated the political process, and finally, after more than a decade of negotiation, the Montreal Protocol was signed in September 1987. Richard Benedick, the chief US negotiator, said at the time that this was 'an application of the precautionary principle'! Initially there were only modest controls (a $50 \%$ reduction in CFC production by 1999), but fortunately the Protocol was able to react to evolving politically independent scientific evidence, which showed that initial controls were inadequate. This led to a sequence of strengthening amendments which accelerated the phase out of CFC production in middle-income countries by 1996 and in low-income countries by 2010 (figure 1A). Over 10 million tonnes of CFCs were manufactured between the initial hypothesis and implementation of controls, but the exponential, irreversible and very long-term increase in stratospheric CFCs was largely prevented (figure 1B).

\section{MONTREAL PROTOCOL: IMPACT ON INHALED THERAPY}

How has inhaled therapy changed as a result of environmental pressure?' In the 1990s inhaled therapy for asthma and COPD was almost exclusively with CFC-propelled MDIs. Since 1996, CFC-propelled MDIs have been the only major exemption from the Protocol under a clause for 'essential use', meaning that the product is 'necessary for health, safety, or is critical for the functioning of society, and that there are no available technically and economically feasible alternatives or substitutes acceptable from the standpoint of environment and health'. The gradual phase out of CFC MDIs has been managed and monitored by a Medical Technical Options Committee consisting of environmental and pharmaceutical regulators, experts from the pharmaceutical industry and respiratory physicians from around the world. From industry, the conversion from CFC $\mathrm{MDIs}$ to hydrofluorocarbon (HFC) MDIs and dry powder inhalers (DPIs) has required considerable investment, technical skill and persistence, particularly in the new strengthened regulatory framework. ${ }^{3}$ Criteria were established country by country for safe CFC MDI phase out, which required an adequate range of CFC-free alternatives for patients. It will have taken almost 20 years to complete but transition has been a worldwide collaborative success. Many millions of patients with asthma and COPD have safely switched from CFC-propelled inhalers without adverse health outcomes, and most without realising it had happened. The change of inhaler has often been used as an opportunity to optimise therapy with individual patients.

\section{PROGRESS IN PHASEOUT OF CFC MDIs}

In middle-income countries, new production of CFC MDIs has now been completely phased out. In the majority of low-income countries too, manufacturers have made rapid progress, with conversion to HFC MDI and DPI manufacturing plants. This has ensured that locally made and affordable inhalers are available for poorer patients worldwide. Some countries, such as India and Iran, completed their CFC-MDI phase out ahead of schedule. In 2012, three further countries (Argentina, Bangladesh and Pakistan) announced that they would not request CFCs. This leaves China and Russia, who together will likely receive an allocation of 600 tonnes of CFCs in 2012. This is less than $5 \%$ of the volume requested in the first year of essential use allocations for MDIs in 1997. Russia will complete its MDI plant conversion next year and will not request CFCs in 2013. 
China will be the last producer of CFC MDIs, but is making significant progress, with a plan to phase out by 2016 and maybe sooner. China has 23 domestic MDI manufacturers who fall into three groups. Five large companies are investing in research and development (R\&D), factory conversion and inhaler registration. Five medium-sized companies are showing early R\&D commitment but are not close to market. The remaining 13 small companies account for $<5 \%$ of CFC use and for them transition may not be economically viable. Some industrial rationalisation is inevitable. China currently imports about $30 \%$ of its total consumption of 24 million inhalers from multinational pharmaceutical companies. Enabling equitable access for inexpensively produced CFC-free inhalers from other countries in south-east Asia would provide a sufficient range of CFC-free inhalers to safely complete transition.

The China CFC MDI phase out brings other potential challenges for inhaled therapy. For example, MDIs containing isoprenaline are still in use in China and transition may allow this relatively unsafe $\beta$ agonist to be discontinued. Over $70 \%$ of the requested CFCs are for salbutamol MDIs. A review of asthma therapy at a public health and individual patient level may allow a switch to more preventive medicines such as inhaled steroids. One particularly difficult question is how to assess the value of Chinese 'traditional' medicines delivered in CFC MDIs, many of which do not satisfy conventional western measures of efficacy. China is currently reviewing the evidence for their use, especially whether or not delivery in a CFC MDI is essential for human health.

\section{Climate ChANGE AND OZONE}

There is long debate about the interactions between climate change and the ozone layer. Controlling CFCs has had unpredicted effects. It turned out that CFCs are also potent global warming gases and CFC phase out resulted in unintended major benefits in substantially delaying climate change by over 30 years. It has been estimated that without the Protocol, the world would already be $3^{\circ} \mathrm{C}$ warmer. ${ }^{4}$ In contrast, and on the downside, the ozone-friendly HFCs developed to replace CFCs (eg, in refrigeration, air conditioning and $\mathrm{MDIs}$ ) are also greenhouse gases, now considered unsafe for the climate. HFC production is increasing rapidly (from 300000 tonnes/ year currently to a projected 900000
A

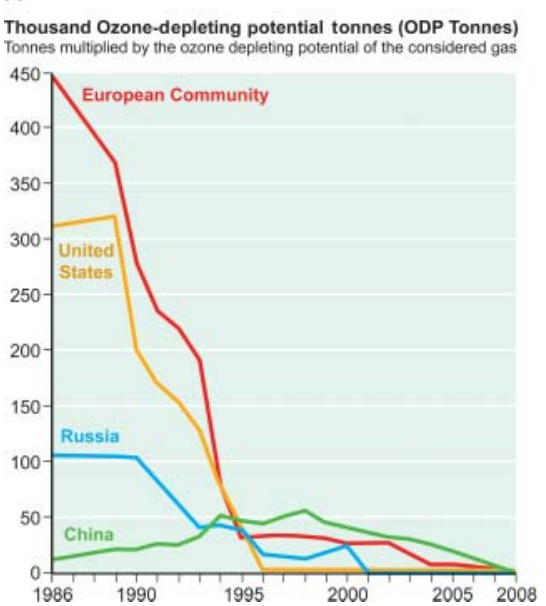

B

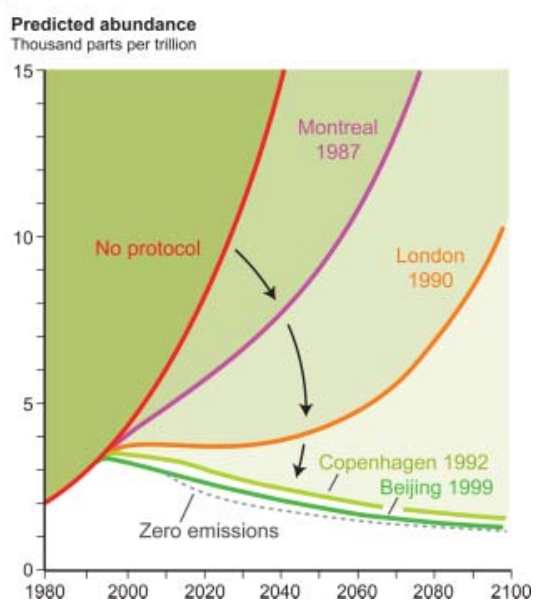

Figure 1 Effect of the Montreal Protocol on chlorofluorocarbon (CFC) production. (A) Rapid reductions in CFC production in different regions following the decision to phase out in middle-income countries by 1996 and in low-income countries by 2010. (B) Effect of strengthening amendments on atmospheric chlorine loading. Without these, chlorine loading would have been exponential and irreversible.

tonnes/year by 2018), and will have a potentially catastrophic impact on global warming if production is not controlled. ${ }^{5}$ Alternatives to HFCs, such as ammonia and carbon dioxide, are now available for a range of uses including air conditioning and refrigeration, and have much lower climate impacts. Current HFC use in MDIs is about 9000 tonnes (about 3\% of total use).

There is little threat in the near term to HFC use in MDIs. The pharmaceutical industry, in good faith, has made considerable efforts and committed extensive resources to develop $\mathrm{HFC} \mathrm{MDIs}$, and phasing out HFCs in MDIs at this time would not be in anyone's best interests, especially patients with asthma and COPD. However, HFC-propelled MDIs have about 30 times the global-warming potential of the equivalent multidose DPIs. DPIs already account for about $50 \%$ of world use of inhalers and novel aqueous sprays are also becoming available. So, over the next $10-20$ years it will be increasingly difficult to make a case for the continued use of HFC-propelled MDIs. Physicians and patients should consider the environmental impact when choosing a new inhaler.

\section{RECOVERY OF THE OZONE LAYER?}

There is controversy over which international treaty should tackle the accelerating use of HFCs in the context of climate change. Climate change issues are usually tackled by the UN Framework Convention on Climate Change (UNFCCC). But the Montreal Protocol, through its ozone protection role, has inadvertently created the problem and is well placed to provide solutions. It has a tried and tested the system for testing and phasing in new technologies when they are determined to be safe and cost effective. In 2011, proposals for HFC controls within the Montreal Protocol were made by the USA, Canada and Mexico, and by the Federated States of Micronesia who have by far the most to lose. However, several countries including Brazil, China and India blocked these proposals in favour of having HFCs dealt with by UNFCCC (UNEP/OzL.ProWG.1/ $31 / 5)$. Unfortunately the recent climate meetings in Capetown and Rio in December also made no progress. This is critical because the implementation of the proposed HFC controls over the next 40 years could save the equivalent of 70 90 gigatonnes of carbon dioxide, comparable to burning all of the world's oil. It is imperative that a political turf war between protocols is not used as an excuse for inaction on HFCs. This issue is far too important.

So, what about the ozone layer itself? Recent data suggest that further ozone depletion is occurring from plumes of water vapour entering the atmosphere as a result of summer storms induced by climate change. ${ }^{6}$ Last year, ozone depletion was even detected in the northern hemisphere. Because of the long atmospheric lifetime of CFCs, the ozone layer will not recover until at least 2060. Since the impact of increased UVB exposure on skin is lifelong, a 
Per million inhabitants per year
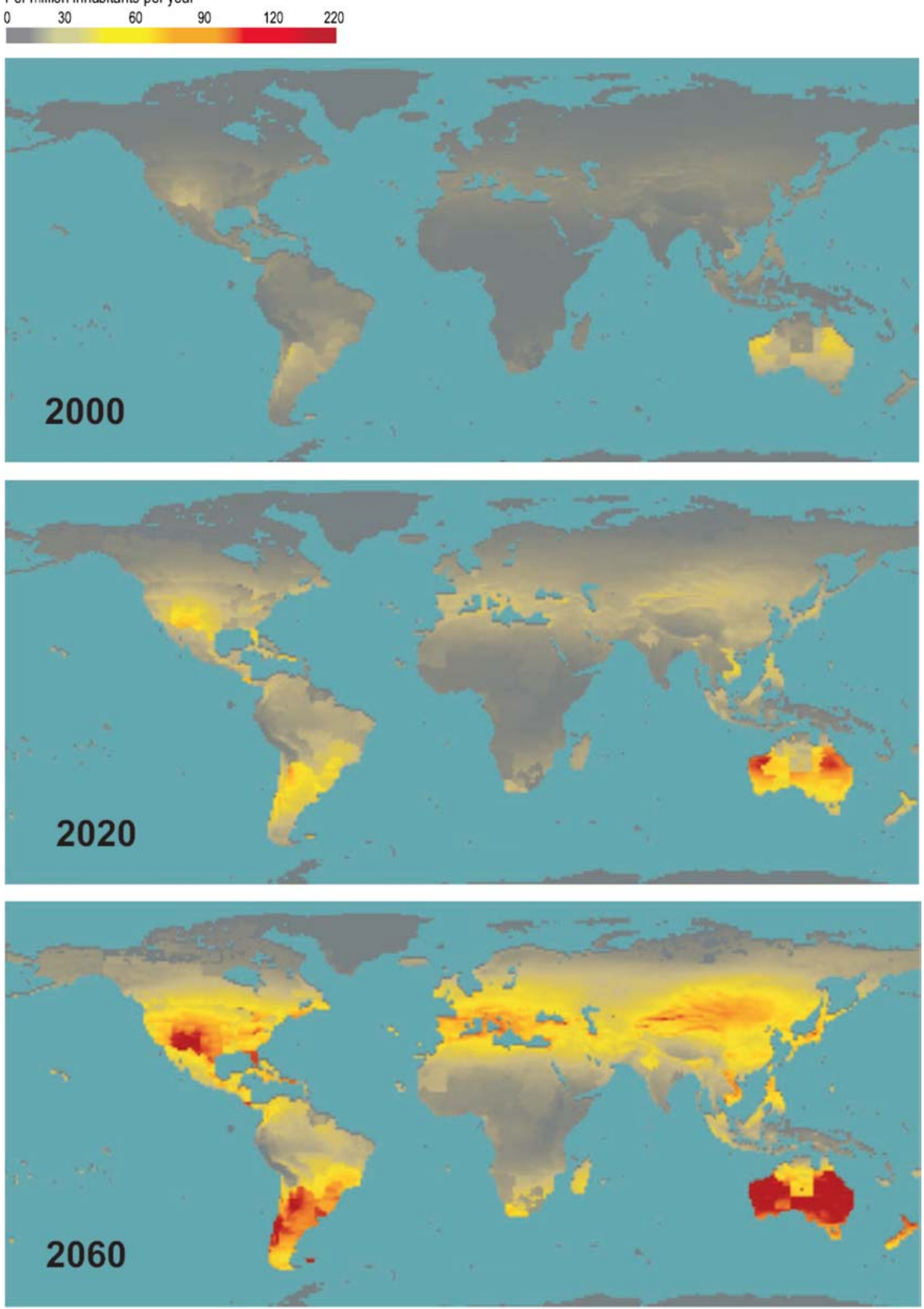

Figure 2 Number of extra skin cancer cases related to increased ultraviolet radiation (Dutch National Institute for Public Health and Environment 2007). ${ }^{7}$

major increase in skin cancer has started, which will continue throughout the twenty-first century (figure 2). So, an environmental insult which started over 40 years ago will continue to damage health for another 100 years. Physicians know that prevention is much better than cure. Surely there is a lesson here for climate change?

Acknowledgements Professor Woodcock is Co-Chair of the Montreal Protocol, Medical Technical Options Committee (for conflict of interest statement, see www.ozone.org). The views contained within this article are those of the author and do not represent the official view of the UN Environment Programme or the
Montreal Protocol's Technical Committees. On behalf of patients with asthma and COPD worldwide, the author thanks the Medical Technical Options Committee Co-Chairs Dr Helen Tope and Mr Jose Pons for 16 years of outstanding voluntary commitment.

\section{Competing interests None.}

Provenance and peer review Commissioned; internally peer reviewed. 
Received 24 August 2012

Accepted 24 August 2012

Published Online First 27 September 2012

Thorax 2012;67:1028-1031.

doi:10.1136/thoraxjnl-2012-202628

\section{REFERENCES}

1. Molina MJ, Rowland FS. Stratospheric sink for chlorofluorocarbons: chlorine atom catalysed destruction of ozone. Nature 1974;249: 810-14.

2. Farman JS, Gardiner BG, Shanklin JD. Large losses of total ozone in Antarctic reveal seasonal $\mathrm{ClO} / \mathrm{NO}_{\mathrm{x}}$ interactions. Nature 1985;315:207-10.

3. Hendeles L, Colice G, Meyer RJ. Withdrawal of albuterol inhalers containing chlorofluorocarbon propellants. N Engl J Med 2007;356:1344-51.

4. Anderson SO, Sarma KM, Taddonio KN. Technology Transfer for the Ozone Layer. Earthscan, London 2007:23-43.
5. Velders GJM, Anderson SO, Daniel JS, et al. The importance of the Montreal Protocol in protecting climate. Proc Nat Acad Sci USA 2007;104: 4814-19.

6. Anderson JG, Wilmouth DM, Smith JB, et al. UV dosage levels in summer: increased risk of ozone loss from convectively injected water vapor. Science 2012;337:835-9.

7. Dutch National Institute for Public Health and Environment, 2007. www.rivm.nl/milieuStoffen/ straling/zomerthema_uw (accessed 3 Sep 2012).

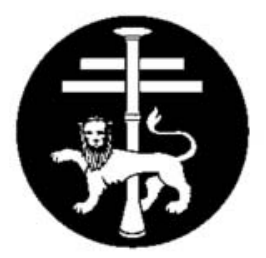

\title{
British Thoracic Society
}

\section{BTS SHORT COURSE}

\section{Practical update on the Management of Pulmonary Embolism}

A practical and interactive BTS short course based on real-life medicine and tackling key questions on Pulmonary Embolism

\section{April 2013, The Hatton, London}

Limited places so early booking is advised.

For more information and to book your place on a BTS short course in 2013, visit:

\author{
www.brit-thoracic.org.uk
}

Working for healthier lungs 